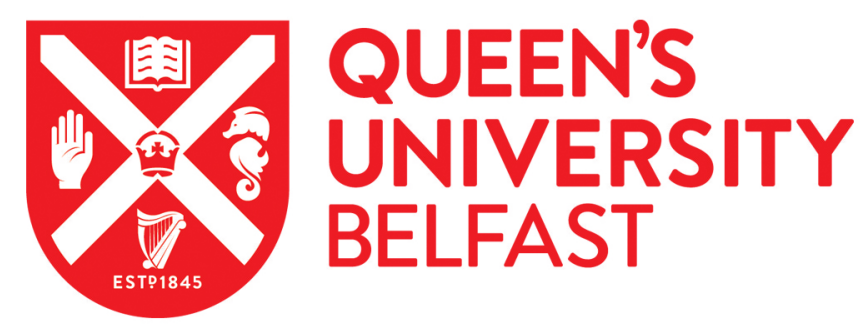

\title{
Production and testing of novel photocatalytic TiO2 surface-exposed nanoparticle (TiO2-SEN) thin plastic films
}

\author{
McNeill, A., Wells, N., Xu, Y., Li, X., Bell, S. E. J., \& Mills, A. (2019). Production and testing of novel \\ photocatalytic TiO2 surface-exposed nanoparticle (TiO2-SEN) thin plastic films. Journal of Photochemistry and \\ Photobiology A: Chemistry, 369, 142-149. https://doi.org/10.1016/j.jphotochem.2018.10.025
}

Published in:

Journal of Photochemistry and Photobiology A: Chemistry

\section{Document Version:}

Peer reviewed version

Queen's University Belfast - Research Portal:

Link to publication record in Queen's University Belfast Research Portal

\section{Publisher rights}

Copyright 2018 Elsevier.

This manuscript is distributed under a Creative Commons Attribution-NonCommercial-NoDerivs License

(https://creativecommons.org/licenses/by-nc-nd/4.0/), which permits distribution and reproduction for non-commercial purposes, provided the author and source are cited.

\section{General rights}

Copyright for the publications made accessible via the Queen's University Belfast Research Portal is retained by the author(s) and / or other copyright owners and it is a condition of accessing these publications that users recognise and abide by the legal requirements associated with these rights.

\footnotetext{
Take down policy

The Research Portal is Queen's institutional repository that provides access to Queen's research output. Every effort has been made to ensure that content in the Research Portal does not infringe any person's rights, or applicable UK laws. If you discover content in the Research Portal that you believe breaches copyright or violates any law, please contact openaccess@qub.ac.uk.
} 


\title{
Production and Testing of Novel Photocatalytic $\mathrm{TiO}_{2}$ Surface- Exposed Nanoparticle ( $\mathrm{TiO}_{2}$-SEN) Thin Plastic Films
}

Aaron McNeill, Nathan Wells, Yikai Xu, Xinyuan Li, Steven E. J. Bell and Andrew Mills*

School of Chemistry and Chemical Engineering, David Keir Building, Stranmillis Road, Belfast, BT9 5AG, UK.

\begin{abstract}
Flexible, surface-active, polystyrene-based, optically transparent films, embedded with a coating of commercially sourced titanium dioxide nanoparticles (Evonik P25), are made by coupling the protonated $\mathrm{TiO}_{2}$ particles with an anionic phase transfer agent (tetraphenylborate), to create an ion paired species that is drawn to a water/dichloromethane (DCM) interface to form a monolayer. The latter is subsequently embedded in a thin polystyrene (PS) film, typically $2.5 \mu \mathrm{m}$ thick, by allowing the DCM to evaporate. The resulting clear $\mathrm{TiO}_{2}$ Surface-Exposed Nanoparticle $\left(\mathrm{TiO}_{2}-\mathrm{SEN}\right)$ thin plastic films are characterised using scanning electron microscopy (SEM) and found to have $25.3 \pm 5.4 \mathrm{~nm}$ nanoparticles exposed to the air on one side and PS on the other. The photocatalytic activity of these films is demonstrated using a number of different tests including: the photooxidation of 4-chlorophenol (4-CP) and methylene blue (MB) and the photoreduction of resazurin (Rz) and MB. In most of these tests the photoactivity of the film is more than double compared against that of a commercial photocatalytic film, Activ ${ }^{\mathrm{TM}}$.
\end{abstract}

Keywords: $\mathrm{TiO}_{2}$, photocatalysis, 4-chlorophenol, methylene blue, resazurin 


\section{Introduction}

Nanomaterials have been the subject of increasing research interest, due to their novel properties compared to those of the bulk material. The change in optical [1], electronic [2] and in some cases magnetic properties [3] is a result of the quantum confinement effect, in which the energy levels of the particle become discrete when its diameter approaches the de Broglie wavelength of the electron wavefunction [4]. These properties can also result from the interaction between nanoparticles when packed in two- or three-dimensional arrays [5]. Nanoparticles are also of particular interest in catalysis, due to their large surface area to volume ratio. However, due to their size, it can often be difficult to separate the nanoparticles from the reaction mixture, especially on a large scale.

A common approach to creating a packed 2D array of nanoparticles is via a self-assembly synthetic route, a notable example of which are Metal Liquid-Like Films (MeLLFs), which are formed through the electrostatic attraction between charged aqueous colloidal nanoparticles of metals, typically $\mathrm{Ag}$ or $\mathrm{Au}[6,7]$, and hydrophobic promoter molecules (usually a phase transfer agent) of opposing charge. The preparation of a MeLLF is very simple; an aqueous colloid of electrostatically stabilised, i.e. charged, nanoparticles are shaken with the corresponding promoter/phase transfer agent, dissolved in an organic solvent with a suitably low miscibility with water such as chlorinated solvents. Shaking this twosolution mix produces emulsion droplets with the colloidal metal particles assembled as a film at the droplet surfaces. When the emulsion is left to settle, the droplets coalesce to form a monolayer of colloidal particles at the final interface of the two immiscible solvents, usually water and dichloromethane (DCM). Although the term 'MeLLF' implies that such a monolayer can only be made only with metal nanoparticles, such monolayers have also been formulated using non-metal and metal oxide nanoparticles, such as $\gamma-\mathrm{Fe}_{2} \mathrm{O}_{3}$ [8], silica and titanium dioxide [9]. The main obstacle of using MeLLFs for different applications is that they are not robust and so cannot be used outside of the initial liquid-liquid interface at which they are formed, which obviously places a severe constraint on how and where they can be used.

Recently, this group has reported a method for preparing robust, flexible 2D MeLLF films involving their deposition on a thin polymer film bed [10]. In these nanoparticle polymer films, or 'Surface-Exposed Nanoparticle', i.e. SEN, plastic films, the nanoparticles are partially embedded in the polymer film, usually polystyrene (PS), but other polymers have been used [10]. Thus, Au- or Ag-SEN plastic films have been used to catalyse reactions or 
promote the detection of analytes by SERS [10]. Despite the formation of interfacial monolayers of metal oxide nanoparticles, no SEN plastic films made from such nanoparticles have been reported to date. $\mathrm{TiO}_{2}$-coated plastic films have been reported previously and are usually prepared using techniques such as high-power impulse magnetron sputtering [11], sol-gel deposition $[12,13]$ and polymer extrusion using photocatalytic powders [14]. The former two processes produce clear films but can usually only be deposited on thick $(>100$ $\mu \mathrm{m})$ and therefore not very flexible plastic films either due to high local temperatures, as in magnetron sputtering, or the need for a post-annealing step, as in sol-gel deposition. In addition, an undercoating of silica is often required to prevent the photocatalyst from degrading the polymer substrate and to provide the necessary adhesion for the $\mathrm{TiO}_{2}$ film.

Thin films of nanoparticulate $\mathrm{TiO}_{2}$ are found in many commercial photocatalytic products, such as self-cleaning glass [15], tiles [16], awning material [17], concrete [18] and paint [19]. Of these, the most well-known photocatalytic product is photocatalytic glass, an example of which is Activ $^{\mathrm{TM}}$, sold by Pilkington Glass-NSG. Activ ${ }^{\mathrm{TM}}$ is made by chemical vapour deposition, CVD, in which a gaseous $\mathrm{TiO}_{2}$ precursor is brought in contact with hot glass $\left(>450^{\circ} \mathrm{C}\right)$, whereupon the thermal decomposition of the precursor occurs on the surface of the glass and results in the formation of a thin (ca. $15 \mathrm{~nm}$ thick) layer of anatase $\mathrm{TiO}_{2}$ bound to the surface [20]. Activ ${ }^{\mathrm{TM}}$, is readily available commercially and often used as a benchmark with which to compare the performance of any new, nanoparticulate, thin $\mathrm{TiO}_{2}$ photocatalytic films, including those on plastic films [21]. Thus, in this work we describe the first preparation and characterisation of a $\mathrm{TiO}_{2}-\mathrm{SEN}$ thin plastic film $(<<100 \mu \mathrm{m})$ and compare and contrast its performance as a photocatalytic film, with that of a commercial nanoparticulate film, namely Activ ${ }^{\mathrm{TM}}$. Note, that unlike Activ ${ }^{\mathrm{TM}}$ glass, the $\mathrm{TiO}_{2}-\mathrm{SEN}$ plastic film is inexpensive, easy and simple to make, with no high-temperature annealing step; in addition, the film itself is flexible. However, like Activ ${ }^{\mathrm{TM}}$ glass, it is optically clear and, as we shall see, photocatalytically active.

\section{Experimental Section}

\subsection{Materials}

Unless otherwise stated, all chemicals were purchased from Sigma-Aldrich and used as received. $\mathrm{P} 25 \mathrm{TiO}_{2}$ powder was supplied by Evonik, and comprises particles (fundamental particle size: ca. $25-30 \mathrm{~nm}$ ) which are a mixture of anatase and rutile phases (typically 70 $80 \%$ anatase), with a surface area of $c a .50 \mathrm{~m}^{2} \mathrm{~g}^{-1}[22]$. 


\section{2. $\mathrm{TiO}_{2}$ Dispersion}

An opalescent dispersion of the $\mathrm{P} 25 \mathrm{TiO}_{2}$ nanoparticles particles P25 solutions was made using a combined sonication-centrifugation process that has been reported elsewhere [23]. Briefly, in this method, $\mathrm{P} 25$ powder $\left(1 \mathrm{~g} \mathrm{~L}^{-1}\right)$ is dispersed in $0.01 \mathrm{M} \mathrm{HCl}(\mathrm{pH} 2)$, and the large, aggregated $\mathrm{TiO}_{2}$ particles broken up by exposure to $5 \mathrm{~min}$ of ultrasound delivered by a tapered microtip Soniprobe (Lucas Dawe Ultrasonics). The resulting dispersion of $\mathrm{TiO}_{2}$ is then centrifuged three times at $2500 \mathrm{rpm}$ for 20 minutes (Hermle Z200A Centrifuge), so as to allow the removal of the remaining large, aggregated particles which formed a solid residue. The resulting $\mathrm{TiO}_{2}$ colloid has a slight translucency and a pale brown/yellow colour, as illustrated by the photograph in Figure S1. In this work, the loading of the $\mathrm{TiO}_{2}$ colloid was determined as $c a .67 \mathrm{mg} \mathrm{L}^{-1}$. In contrast, a dispersion of the same loading with $\mathrm{P} 25$ powder is opaque (see Figure S1), due to the higher proportion of highly scattering $\mathrm{TiO}_{2}$ aggregates.

\section{3. $\mathrm{TiO}_{2} \mathrm{Surface}$ Exposed Nanoparticle $\left(\mathrm{TiO}_{2}-\mathrm{SEN}\right)$ Plastic Film}

The method employed for producing the $\mathrm{TiO}_{2}-\mathrm{SEN}$ plastic film used through this work was similar to that used for making MeLLF films, but with an organic-soluble polymer, such as polystyrene, added to the system. The key synthetic steps are illustrated in the schematic in Figure 1.

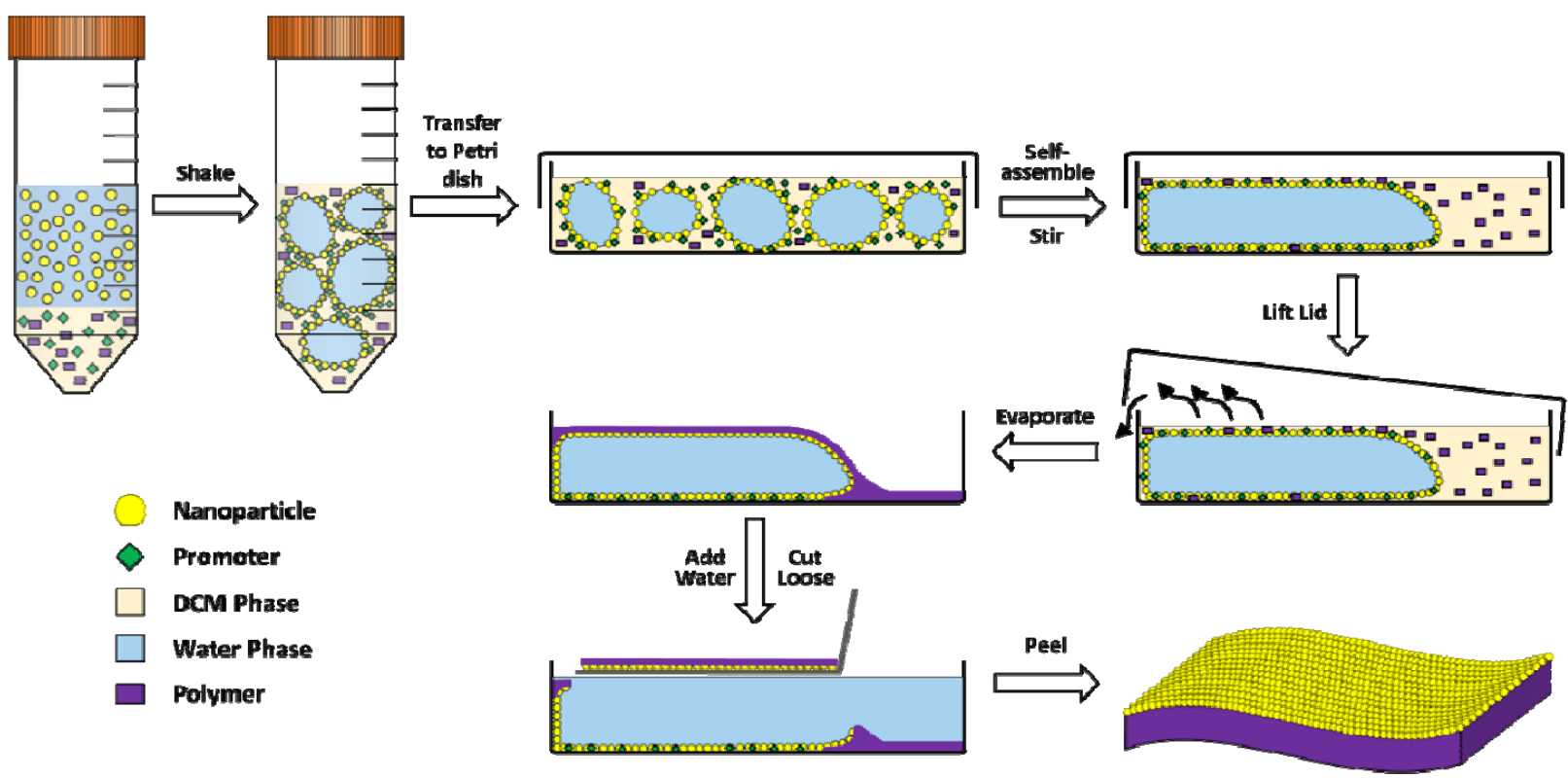

Figure 1. Schematic illustration of the fabrication process of $\mathrm{TiO}_{2}$ Surface-Exposed Nanoparticle $\left(\mathrm{TiO}_{2}-\mathrm{SEN}\right)$ plastic film. 
Briefly, $5 \mathrm{~mL}$ of the aqueous $\mathrm{TiO}_{2}$ dispersion were shaken with $1.2 \mathrm{~mL}$ of $10^{-4} \mathrm{M}$ aqueous solution of the promoter/phase transfer agent (sodium tetraphenylborate, NaTPB), to which were added subsequently $3 \mathrm{~mL}$ of a $0.05 \mathrm{~g} \mathrm{~mL}^{-1}$ solution of polystyrene (Molecular Weight $=$ 192,000) in DCM and the whole biphasic mixture of solutions shaken vigorously. The $\mathrm{pH}$ of the aqueous $\mathrm{TiO}_{2}$ dispersion was 2 and, since the pzc of P25 is ca. 5.9 [24], it follows that the $\mathrm{TiO}_{2}$ particles are positively charged, and so readily ion-pair with the lipophilic anions of the phase transfer agent, NaTPB, which then collect at the water/DCM interface of the emulsion droplets formed upon shaking the biphasic solution, as illustrated in Figure 1. The resulting emulsion, generated by shaking, was transferred to a polypropylene $50 \mathrm{~mm}$ diameter Petri dish and the mixture was gently swirled until a thin polymer layer formed on top of the aqueous phase, due to the slow evaporation of the DCM. The lid of the Petri dish was then lifted off slightly to accelerate the evaporation process and as the organic solvent evaporated, the polystyrene layer thickened. Note: as indicated in Figure 1, as a consequence of this evaporation process the $\mathrm{TiO}_{2}$ nanoparticles, initially gathered as a $2 \mathrm{D}$ monolayer at the water DCM interface, and whilst still exposed on the aqueous side of the interface, slowly partially embed themselves in the polymer film forming on the DCM side. After a couple of hours, all the DCM had evaporated, and the transparent $\mathrm{TiO}_{2}$-coated PS film was cut out with a scalpel, and water added to float off the plastic film. Once floated, it was then scooped out and placed on a flat hydrophobic surface (to prevent film sticking) and allowed to dry further for at least an hour. The $\mathrm{TiO}_{2}-\mathrm{SEN}$ plastic films were then stored in the dark under ambient conditions. For comparison, a blank SEN plastic film (i.e. a thin PS film) was also made using this method but with $5 \mathrm{~mL}$ of double distilled water replacing that of the $\mathrm{P} 25 \mathrm{TiO}_{2}$ colloid. Note that unlike SEN films based on metal colloids, which are usually highly coloured, a $\mathrm{TiO}_{2}$ SEN plastic film is clear and colourless and identical in appearance to that of a plain PS film made using the same procedure.

\subsection{Aqueous Solution Photocatalytic Oxidation and Reduction Tests}

In this study the photocatalytic activities of the $\mathrm{TiO}_{2}$-SEN plastic film and a sample of Activ $^{\mathrm{TM}}$ glass were probed using a number of different aqueous solution test systems, namely, (a) the photooxidation of: (i) 4-chlorophenol (4-CP) and (ii) methylene blue (MB) by oxygen and (b) the photoreduction of resazurin by glycerol. In all cases these reactions were studied using a $1 \mathrm{~cm}$ fluorescence cuvette as the reactor and UV-Vis spectrophotometry was used as the method of monitoring reaction progress. In the case of the $\mathrm{TiO}_{2}-\mathrm{SEN}$ plastic film a $1 \mathrm{~cm}^{2}(8 \mathrm{~mm} \times 12.5 \mathrm{~mm})$ piece of the $\mathrm{TiO}_{2}-\mathrm{SEN}$ plastic film was fixed to the wall of the 
cuvette using double-sided Sellotape. In the case of Pilkington Activ ${ }^{\mathrm{TM}}$ glass, a small window of $1 \mathrm{~cm}$ was cut into a cuvette and a piece of $\operatorname{Activ}^{\mathrm{TM}}$ attached to the side so as to act as a photocatalytic window. The reaction solution volume was always $3 \mathrm{~mL}$ and was always stirred using a Teflon-coated crown shaped magnetic stirrer bar. The cuvette reactor was placed inside a UV-Vis spectrophotometer so that the photocatalyst film was parallel to the monitoring beam. This arrangement allowed the photocatalyst film under test to be irradiated with UV light from the UV LED, which was placed perpendicular to the monitoring beam, whilst monitoring any change in UV-Vis spectrum of the reaction solution at the same time. The irradiance of the UV light shining on the film in this setup was typically $42 \mathrm{~mW} \mathrm{~cm}^{-2}$ and was provided by a $365 \mathrm{~nm}$ UV LED, vide infra. A schematic illustration of the irradiation set up is illustrated in Figure S2.

\subsection{Ink Film Photocatalytic Tests}

As well as aqueous photocatalytic systems, the photoactivity of the $\mathrm{TiO}_{2}$-SEN plastic film, and that of a sample of Pilkington Activ ${ }^{\mathrm{TM}}$, were assessed by monitoring the photoreduction of the dyes: resazurin, Rz, and methylene blue, MB, in ink coatings. The Rz and MB inks were made using the following formulation: $1.5 \mathrm{wt} \%$ aqueous hydroxyethylcellulose (HEC) $(\mathrm{MW}=250,000)$ solution, $0.1 \mathrm{~g} \mathrm{~mL}^{-1}$ glycerol, $1 \mathrm{mg} \mathrm{mL}^{-1}$ of dye (Rz or MB) and $20 \mathrm{mg}$ of polysorbate 20 (PS20). Each ink was spread onto the photocatalyst film under test using a Kbar (\#3) [25] to give a wet ink film of thickness $24 \mu \mathrm{m}$, which, when allowed to dry in the dark (20 min), forms an ink film of thickness ca. $2.1 \mu \mathrm{m}$, as determined by analysing the interference fringes of a UV-Vis spectrum using the Swanepoel method [26]. Once dried, these ink film coatings, on the photocatalytic films under test, were then irradiated with UVA light $\left(2 \times 15 \mathrm{~W}\right.$ BLB tubes, $\lambda_{\max }$ emission: $352 \mathrm{~nm}$, irradiance: $1.6 \mathrm{~mW} \mathrm{~cm}{ }^{-2}$ ) and the photocatalytically-induced colour change in the film monitored using UV-Vis spectrophotometry.

\subsection{Methods}

All UV-Vis spectrophotometry was performed using an Agilent Cary 60 UV-Vis spectrophotometer. Digital images were taken using a Canon 1200D. FT-IR absorption spectra were recorded using a Perkin Elmer Spectrum 1. Scanning Electron Microscopy was carried out using a FEI Quanta FEG 250 on samples that were first sputter-coated with gold using a Q150T sputter coater (Quorum Technologies). UVA irradiations were performed with 
either a $365 \mathrm{~nm}$ LED (irradiance: $42 \mathrm{~mW} \mathrm{~cm}^{-2}$ ) from RS Components (829-0841, LZ110UV00) or a Blak-Ray ${ }^{\circledR}$ XX-15 lamp housing, fitted with: 2 x $15 \mathrm{~W}$ BLB tubes, $\lambda \max$ emission: $352 \mathrm{~nm}$, irradiance: $1.6 \mathrm{~mW} \mathrm{~cm}^{-2}$ (Cole-Parmer).

\section{Results and Discussion}

\subsection{Characterisation}

The UV-Vis spectrum of the $\mathrm{TiO}_{2}-\mathrm{SEN}$ plastic film, along with that of a PS film without $\mathrm{TiO}_{2}$ and a sample of Activ ${ }^{\mathrm{TM}}$, were recorded and the results are illustrated in Figure 2. In the case of the $\mathrm{TiO}_{2}$-SEN plastic film, by comparing the UV-Vis spectrum with that of the PS film only, the presence of $\mathrm{TiO}_{2}$ is evident from the additional absorbance in the UV region, as is the presence of the PS which has a peak at $260 \mathrm{~nm}$, and which can also be seen in the UV absorption spectrum of the PS only film. The UV absorption spectrum of the sample of Activ ${ }^{\mathrm{TM}}$ also suggests the presence of $\mathrm{TiO}_{2}$, with its strong absorption in the UVA region, although a significant component of this will, in fact, be due to the underlying $4 \mathrm{~mm}$ glass support substrate. The photograph of the $\mathrm{TiO}_{2}-\mathrm{SEN}$ plastic film in Figure 2, held between tweezers, helps to illustrate its striking optical clarity, which appears on a par to that of Activ $^{\mathrm{TM}}$ glass, and its delicate nature (at $2.5 \mu \mathrm{m}$, it is $>16$ times thinner than a human hair).

The organic nature of the support substrate in the $\mathrm{TiO}_{2}-\mathrm{SEN}$ plastic film, namely polystyrene, i.e. PS, raises the concern that the PS is likely to be readily photo-oxidised by the $\mathrm{TiO}_{2}$ particles when the $\mathrm{TiO}_{2}-\mathrm{SEN}$ plastic film is exposed to ultra-bandgap irradiation. This feature would be an obvious flaw in this new material, although some in-built slow photodegradation, might be attractive for some applications. 

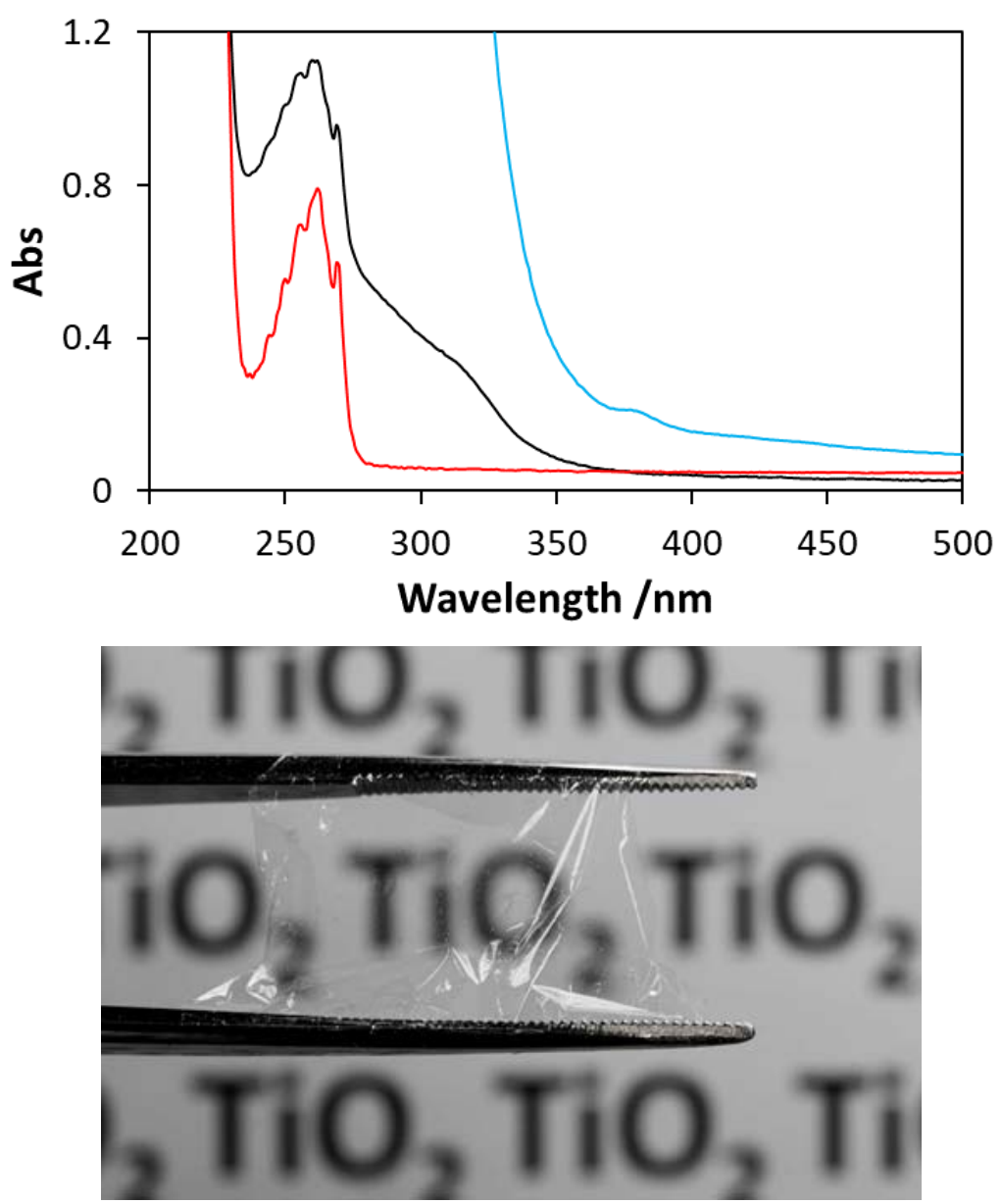

Figure 2. (a) UV-Vis spectra of a $\mathrm{TiO}_{2}-\mathrm{SEN}$ plastic film (black), Pilkington Activ ${ }^{\mathrm{TM}}$ glass (blue) and a blank polystyrene (red). (b) Photograph of a $\mathrm{TiO}_{2}-\mathrm{SEN}$ plastic film held by a set of tweezers over a printed sheet to illustrate its clarity.

However, PS is quite difficult to oxidise, even by semiconductor photocatalysis, and other work carried out on the $\mathrm{TiO}_{2}$-SEN plastic film, using FTIR spectroscopy to monitor the PS, revealed no change in the PS part of the $\mathrm{TiO}_{2}-\mathrm{SEN}$ plastic film after 1 week of continuous UVA irradiation ( $365 \mathrm{~nm}$ LED, irradiance: $42 \mathrm{~mW} \mathrm{~cm}^{-2}$ ). Indeed, the film remained crystal clear throughout the prolonged irradiation and retained its original photocatalytic activity, as assessed using the $\mathrm{Rz}$ ink test. Thus, the $\mathrm{TiO}_{2}-\mathrm{SEN}$ plastic film appears a relatively stable photocatalytic material, as was also demonstrated in some of the photocatalyst tests, vide infra.

Scanning Electron Microscopy was used to examine the surfaces of the $\mathrm{TiO}_{2}-\mathrm{SEN}$ plastic film, Activ ${ }^{\mathrm{TM}}$ and blank (no $\mathrm{TiO}_{2}$ ) PS film and the results of this work are illustrated in Figure 3. In the $\mathrm{TiO}_{2}$-SEN plastic film, the nanoparticles form a surface-exposed monolayer that is partially embedded in the PS on the one side, but not on the other (Figure S3); the latter SEM was in fact identical in appearance to that of the 'blank' PS film illustrated in Figure 3(d). The amount of $\mathrm{TiO}_{2}$ in a $100 \mathrm{~cm}^{2}$ sheet of the $\mathrm{TiO}_{2}-\mathrm{SEN}$ plastic film, determined 
by burning off the polystyrene in a crucible and weighing the residue, was $520 \mu \mathrm{g}$, making the loading of $\mathrm{TiO}_{2}-\mathrm{SEN}$ plastic film ca. $5.2 \mu \mathrm{g} \mathrm{cm}^{-2}$, which equates to ca. $0.92 \%$ of the mass of the film. SEM measurements of film thickness (see Figure 3(b)) for a typical $\mathrm{TiO}_{2}-\mathrm{SEN}$ plastic film revealed an average value of ca. $2.5 \mu \mathrm{m}$. A close inspection of the SEM for the $\mathrm{TiO}_{2}-\mathrm{SEN}$ plastic film i.e. Figure 3(a), revealed an average particle size of $25.3 \pm 5.4 \mathrm{~nm}$. Similarly, the same analysis of the classic cobblestone appearance [21] of the surface of the sample of Activ ${ }^{\mathrm{TM}}$, see Figure 3(c), revealed an average particle size of $30.2 \pm 2.7 \mathrm{~nm}$.
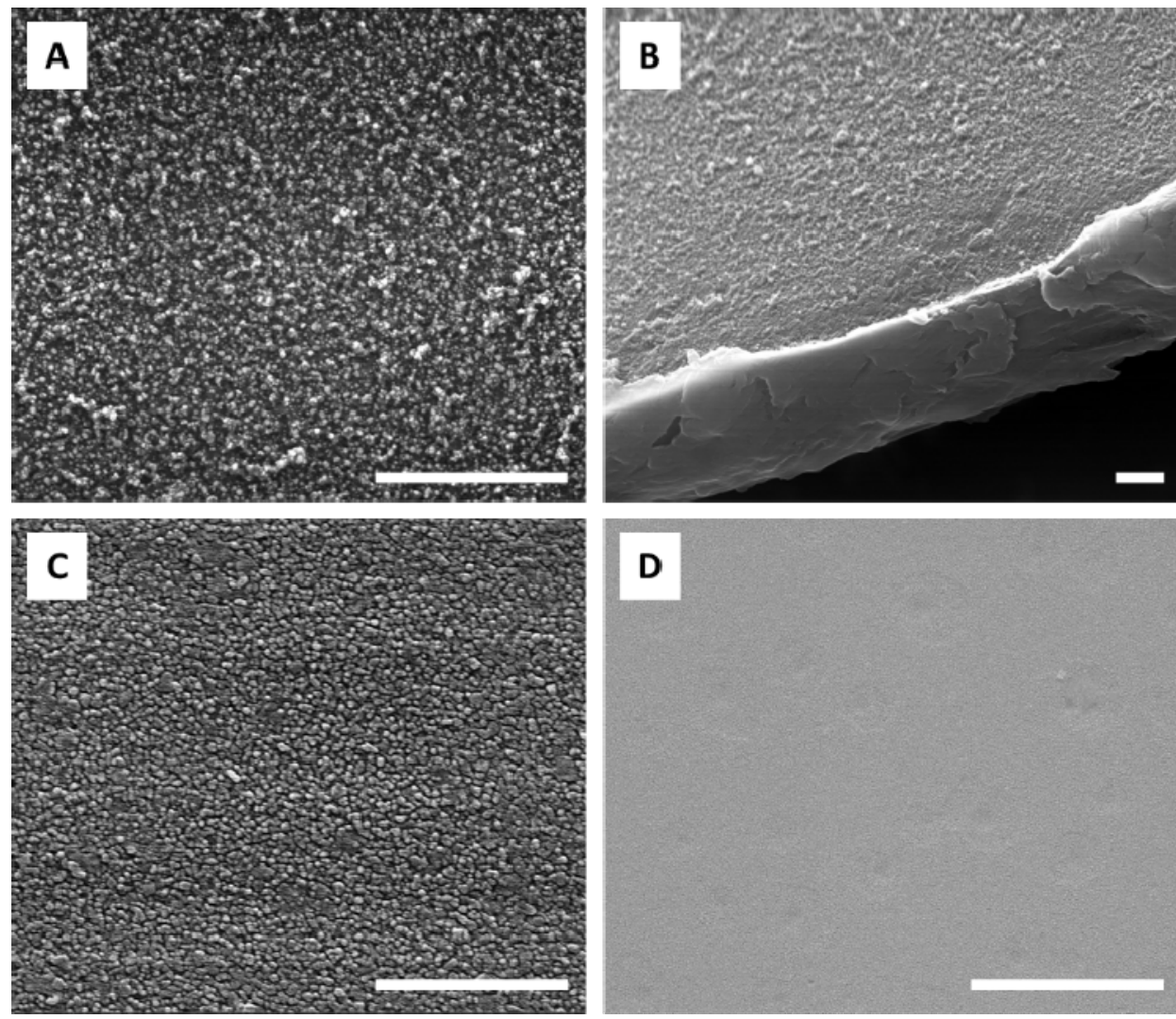

Figure 3. SEM images of a $\mathrm{TiO}_{2}-\mathrm{SEN}$ plastic film, both (a) plan view of the surface and (b) a tilted view of a cut edge, (c) Pilkington Activ $^{\mathrm{TM}}$ glass and (d) a blank SEN film (i.e. PS only - no $\mathrm{TiO}_{2}$ ). Scale bar for all images is $1 \mu \mathrm{m}$.

\subsection{4-Chlorophenol Degradation Test}

One of the most commonly studied solution-based systems for testing new and established photocatalytic materials is the photooxidation of 4-chlorophenol (4-CP) in the presence of oxygen, mediated by $\mathrm{TiO}_{2}[27,28]$, i.e.

$$
\mathrm{C}_{6} \mathrm{H}_{4} \mathrm{ClOH}+\frac{13}{2} \mathrm{O}_{2} \underset{\mathrm{TiO}_{2}}{\longrightarrow} 6 \mathrm{CO}_{2}+2 \mathrm{H}_{2} \mathrm{O}+\mathrm{HCl}
$$


The complete photocatalytic mineralisation of 4-CP by P25 has been well established [ref]. However, since in this work only the disappearance of 4-CP, and any UV/Visible absorbing intermediate species, is observed, it is more correct to refer to this test as the photo-oxidation or destruction of 4-CP, rather than its mineralisation.

4-CP is an ideal test pollutant of UVA absorbing semiconductor photocatalysts, such as $\mathrm{TiO}_{2}$, in that it does not absorb much, if at all, in this wavelength region ( $\lambda_{\max }$ absorption 4$\mathrm{CP}=225$ and $280 \mathrm{~nm}$ ) and so is relatively stable in air-saturated aqueous solution when irradiated with UVA radiation. Although this test is most commonly used to probe the activities of dispersions of photocatalytic powders, which have high surface areas, in this work we use it to probe the activity of the $\mathrm{TiO}_{2}-\mathrm{SEN}$ plastic film and Activ ${ }^{\mathrm{TM}}$, which will have much lower surface areas and so will have a relatively low photoactivity. However, the likely slow rate of destruction of 4-CP exhibited by either film should not pose too much of a problem given the blank (i.e. no photocatalyst coated film) is likely to show little ability to destroy 4-CP.

In this work, $3 \mathrm{~mL}$ of a $2.5 \times 10^{-4} \mathrm{M}$ solution of 4-CP in $0.01 \mathrm{M} \mathrm{HClO}_{4}$ were added to the quartz cuvette 'reaction vessel', with a 'window' of the photocatalyst film under test set in its side (Figure S2). In order to minimise evaporation loss, and yet still ensure the dispersion was fully aerated, the reaction solution was continuously purged with air that had been previously saturated with water, i.e. with a RH value of $100 \%$. The change in the UV-Vis absorption spectrum of the 4-CP reaction solution was monitored as a function of irradiation time for the $\mathrm{TiO}_{2}$-SEN plastic film and the results of this work are illustrated in Figure 4. The spectral changes show that with prolonged (96 h) UV irradiation the 4-CP in solution is completely degraded. The removal of the 4-CP is best represented by a plot of the absorbance of the 4$\mathrm{CP}$ reaction solution at $225 \mathrm{~nm}$, i.e. $\mathrm{Abs}(225 \mathrm{~nm})$, as a function of irradiation time, which is illustrated in the insert diagram in Figure 4, for the $\mathrm{TiO}_{2}-\mathrm{SEN}$ plastic film, blank (just PS) film and the Activ ${ }^{\mathrm{TM}}$ glass. These plots show that although slow, the $\mathrm{TiO}_{2}-\mathrm{SEN}$ plastic film is much more active than Activ ${ }^{\mathrm{TM}}$ in promotingthe photo-oxidation of 4-CP, which in turn is much more effective at 4-CP removal than the blank film. The slow kinetics of both photocatalytic films is due to their low surface areas and the multi-electron $\left(26 \mathrm{e}^{-}\right.$per $4-\mathrm{CP}$ molecule) nature of reaction (1). 


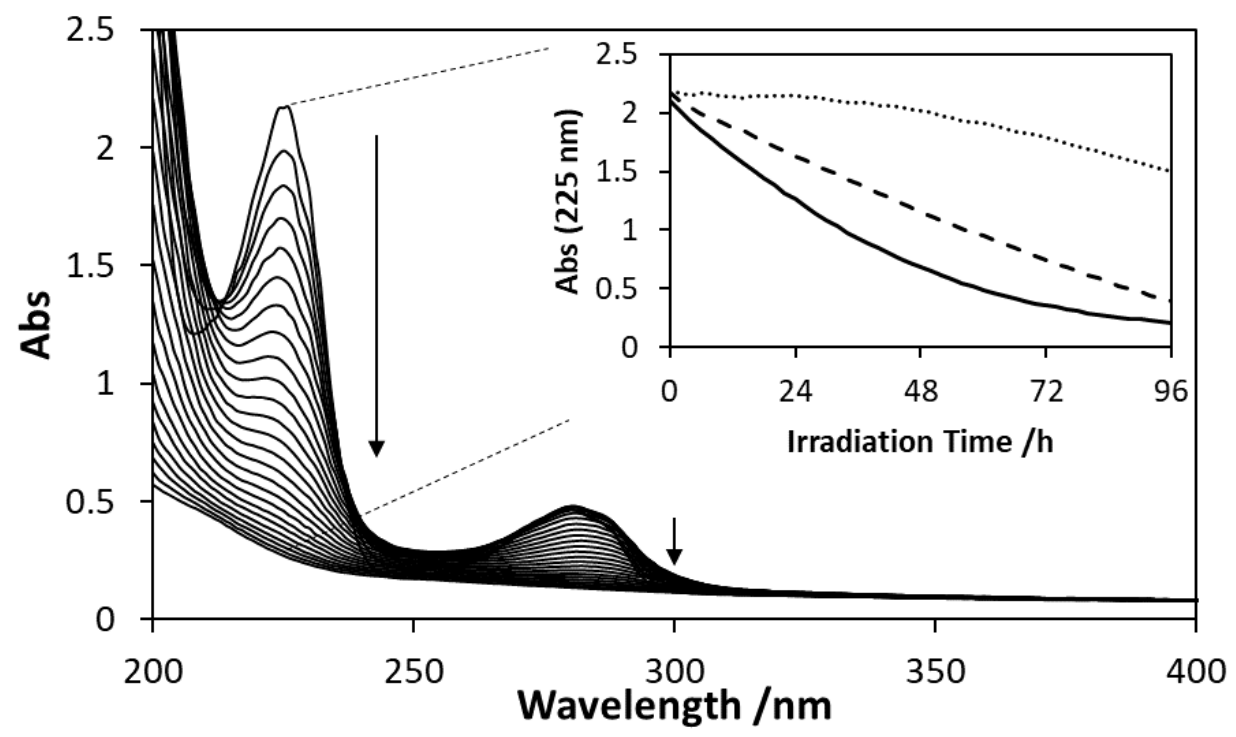

Figure 4. Typical UV-Vis spectra of the degradation of a $2.5 \times 10^{-4} \mathrm{M}$ solution of 4-CP in the presence of a $\mathrm{TiO}_{2}-\mathrm{SEN}$ plastic film irradiated with $365 \mathrm{~nm}$ light (Intensity $=42 \mathrm{~mW} \mathrm{~cm} \mathrm{~cm}^{-2}$ ) over 96 hours in 4 hour intervals. Inset diagram: Plots of the absorbance (at $225 \mathrm{~nm}$ ) of the 4CP solution in the presence of: a $1 \mathrm{~cm}^{2}$ area of a $\mathrm{TiO}_{2}-\mathrm{SEN}$ plastic film (solid line), Pilkington Activ ${ }^{\mathrm{TM}}$ glass (dashed line) and a blank polystyrene film (dotted line) under UV irradiation $\left(365 \mathrm{~nm}, 42 \mathrm{~mW} \mathrm{~cm}^{-2}\right)$, as a function of irradiation time.

A brief analysis of the decay kinetics exhibited by the two films (i.e. $\mathrm{TiO}_{2}$-SEN plastic film and Activ $^{\mathrm{TM}}$ ), as illustrated by the insert diagram in Figure 4, suggest that they are first order with respect to 4-CP, with first order rate constant, k1, values of $(22.2 \pm 0.2) \times 10^{-3}$ and $(12.7$ $\pm 0.2) \times 10^{-3} \mathrm{~h}^{-1}$ for a $\mathrm{TiO}_{2}-\mathrm{SEN}$ plastic film and Activ ${ }^{\mathrm{TM}}$, respectively. The observation of first order decay kinetics for the photo-oxidation of 4-CP is common and usually attributed to the low 'dark' absorption of 4-CP onto $\mathrm{TiO}_{2}$, so that the surface concentration of 4-CP is directly proportional to the concentration of 4-CP in the bulk of solution [24].

The long irradiation times needed in this work to affect the complete destruction of the 4$\mathrm{CP}$, might be expected to expose any tendency in the $\mathrm{TiO}_{2}-\mathrm{SEN}$ plastic film to destroy the underlying PS which binds the $\mathrm{TiO}_{2}$ nanoparticles to its surface. In order to probe this potential problem, a $\mathrm{TiO}_{2}$-SEN plastic film was used repeatedly to photocatalysethe photooxidation of 4-CP. The results of this work are illustrated in Figure 5, by a series of Abs(225 $\mathrm{nm})$ vs irradiation time decay curves and reveal that the $\mathrm{TiO}_{2}-\mathrm{SEN}$ plastic film retains its photoactivity through at least 4 complete cycles of the reaction, with $\mathrm{k}_{1}$ values of 0.023 , $0.026,0.028$ and $0.024 \mathrm{~h}^{-1}$ for the 4 consecutive runs, suggesting that the polystyrene embedding material is refractory and that the $\mathrm{TiO}_{2}-\mathrm{SEN}$ plastic films photocatalytically and physically robust. 


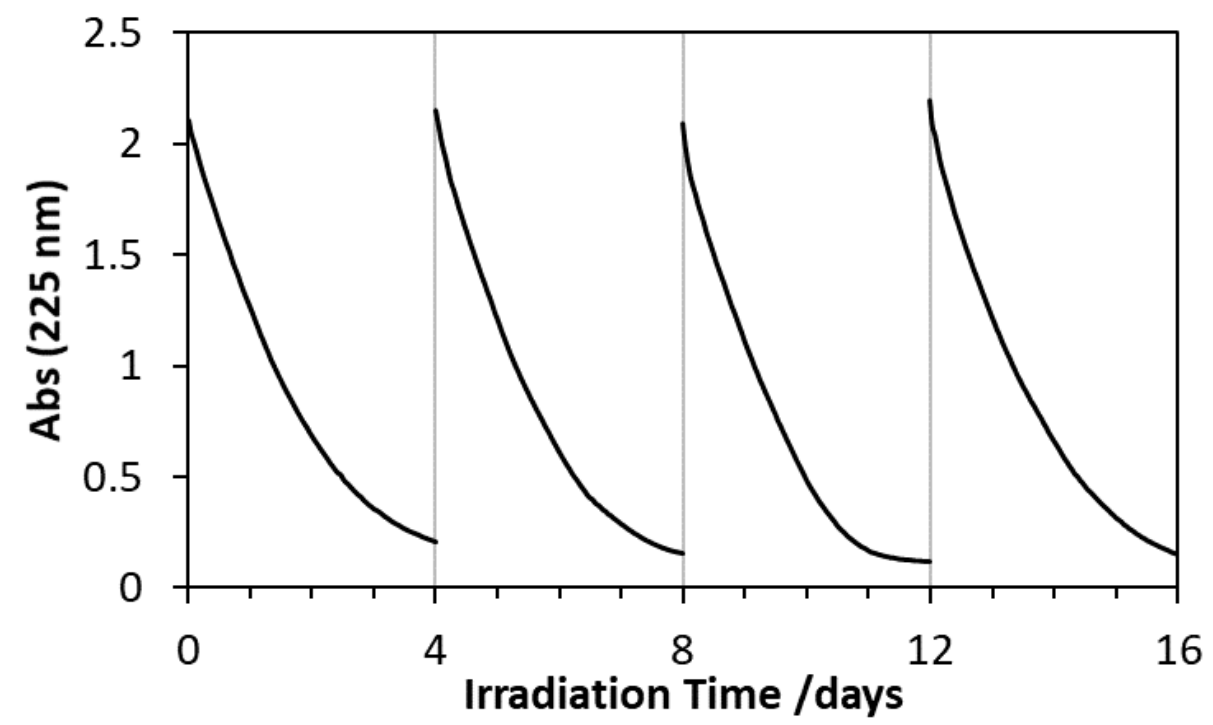

Figure 5. Max absorbance of a 4-CP solution in the presence of a $\mathrm{TiO}_{2}-\mathrm{SEN}$ plastic film under UV irradiation $\left(365 \mathrm{~nm}, 42 \mathrm{~mW} \mathrm{~cm}^{-2}\right)$. Every 4 days, the solution was replaced with fresh $2.5 \times 10^{-4} \mathrm{M} 4-\mathrm{CP}$ solution.

\subsection{Methylene Blue ISO Test}

As noted earlier, the photooxidative mineralisation of 4-chlorophenol is not a common test for new and existing photocatalytic films, but rather of powders. In order to assess the photocatalytic activity of a photocatalytic film, it is more common to employ a dye, usually methylene blue, MB, dissolved in solution. Indeed, the photocatalysed oxidative bleaching of MB is the basis of a well-established ISO test (ISO: 10678:2010 [29]) for assessing selfcleaning activity. In the case of $\mathrm{MB}$, the overall photocatalysed oxidative mineralisation can be summarised as follows:

$$
\mathrm{C}_{16} \mathrm{H}_{18} \mathrm{~N}_{3} \mathrm{SCl}+\frac{51}{2} \mathrm{O}_{2} \underset{\mathrm{TiO}_{2}}{\stackrel{h v \geq E_{\mathrm{b}}}{\longrightarrow}} \mathrm{HCl}+\mathrm{H}_{2} \mathrm{SO}_{4}+3 \mathrm{HNO}_{3}+16 \mathrm{CO}_{2}+6 \mathrm{H}_{2} \mathrm{O}
$$

Once again, the complete photocatalytic mineralisation of MB by P25 has been well established [ref]. However, since in this work only the disappearance of MB, and any $\mathrm{UV} /$ Visible absorbing intermediate species, is observed, it is more correct to refer to this test as the photo-oxidation or bleaching of $\mathrm{MB}$, rather than its mineralisation.

This reaction is a particularly popular test of photocatalytic activity in that the photocatalyst bleaches the dye and so produces a very striking change in colour. In addition, because MB absorbs little in the UVA region, it is very suitable for assessing the activities of UVA absorbing photocatalysts, such as $\mathrm{TiO}_{2}$. It is not, however, suitable for assessing the activity 
of visible light absorbing photocatalysts, as noted in the MB ISO test [29] and elsewhere [30].

Thus, in this work the photocatalytic 'self-cleaning' activity of the $\mathrm{TiO}_{2}-\mathrm{SEN}$ plastic film was tested using a modified version of the MB ISO test [29] in which $3 \mathrm{~mL}$ of a $10 \mu \mathrm{M}$ aqueous solution of MB were placed in the quartz cuvette 'photoreactor' used previously in the 4-CP study, and aerated continuously using humid air. The UV-Vis absorption spectrum of the $\mathrm{MB}$ in the reaction solution was then monitored as a function of irradiation time and the results of this work are illustrated in Figure 6.

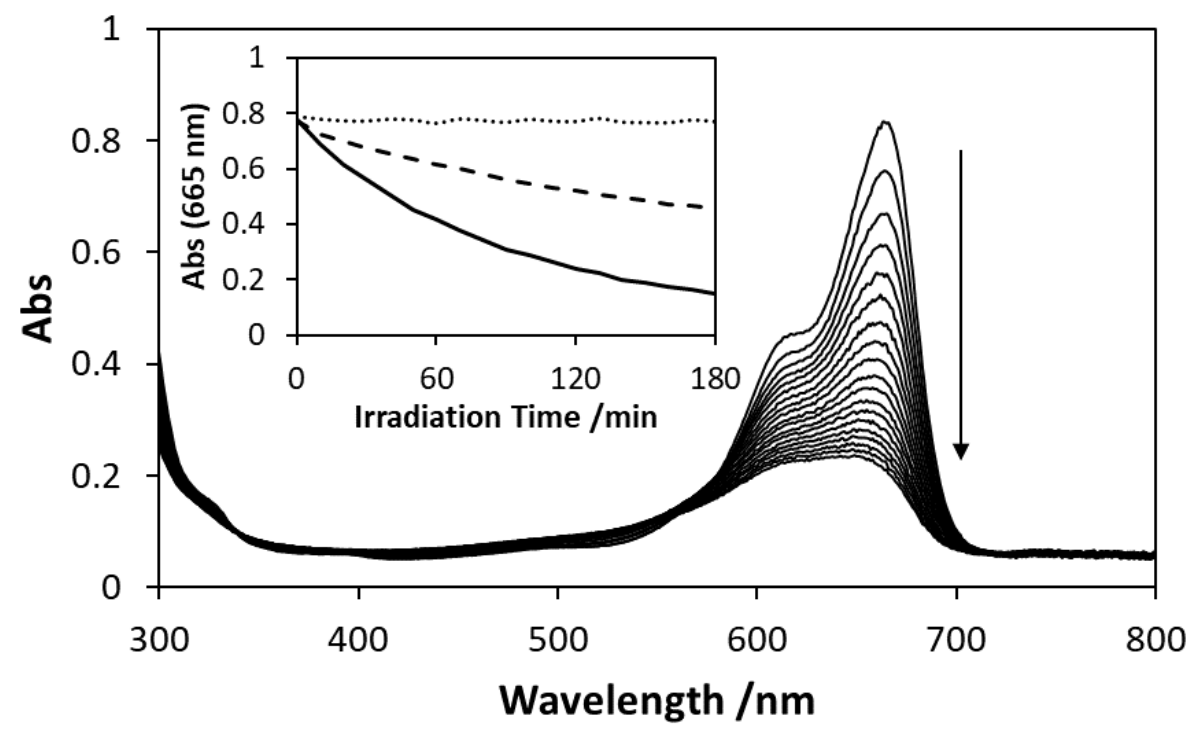

Figure 6. Typical UV-Vis absorption spectral changes of a MB solution $(10 \mu \mathrm{M})$ in a quartz cuvette with a $\mathrm{TiO}_{2}$-SEN plastic film recorded as a function of UVA $(365 \mathrm{~nm})$ irradiation time $\left(42 \mathrm{~mW} \mathrm{~cm}^{-2}\right)$, where the spectra were recorded every $5 \mathrm{~min}$. The insert diagram shows the change of absorbance due to $\mathrm{MB}$ at $665 \mathrm{~nm}$, Abs $(665 \mathrm{~nm})$, recorded under the same experimental conditions as the main diagram, for the $\mathrm{TiO}_{2}-\mathrm{SEN}$ plastic film (solid line), Pilkington Activ ${ }^{\mathrm{TM}}$ glass (dashed line) and a blank polystyrene film (dotted line), as a function of irradiation.

The change in UV-Vis absorption spectrum illustrated in Figure 6 shows that the $\mathrm{TiO}_{2}$-SEN plastic film is able to photocatalyse bleaching of $\mathrm{MB}$, and the most likely eventual photomineralisation of MB via reaction (2). The same experiment was carried out using Activ $^{\mathrm{TM}}$ and a blank (PS only) film and a plot of the decay curves generated, in the form of absorbance due to $\mathrm{MB}$ at $665 \mathrm{~nm}$, i.e. $\operatorname{Abs}(665 \mathrm{~nm})$, as a function of irradiation time, are illustrated in the insert plot in Figure 6. Once again, a brief analysis of the decay kinetics exhibited by the two films (i.e. $\mathrm{TiO}_{2}-\mathrm{SEN}$ plastic film and $\mathrm{Activ}^{\mathrm{TM}}$ ), suggest that they are first order with respect to the concentration of $\mathrm{MB}$, with first order rate constant, $\mathrm{k}_{1}$, values of 0.61 
\pm 0.01 and $0.20 \pm 0.01 \mathrm{~h}^{-1}$ for $\mathrm{TiO}_{2}-\mathrm{SEN}$ plastic film and Activ ${ }^{\mathrm{TM}}$ respectively. The blank polystyrene film as expected did not oxidise MB and thus showed no photoactivity.

\subsection{Rz/Glycerol Photocatalytic Test}

So far, the above tests have focused on assessing the photoactivity of the $\mathrm{TiO}_{2}-\mathrm{SEN}$ plastic film and Activ $^{\mathrm{TM}}$ using traditional photooxidation (of 4-CP or MB) tests. However, recent work carried out by this group [31,32] suggests that it is also possible to assess the photocatalytic activity of a powder or a film via the photoreduction of a dye, thereby producing a rapid, striking and easily monitored colour change, and concomitant oxidation of a sacrificial electron donor, such as glycerol. One of the most common examples of the latter reaction employs Resazurin, Rz, as the (blue) dye, since it can be reduced photocatalytically to pink Resorufin, Rf, in the presence of a sacrificial electron donor, SED, such as glycerol. Although more commonly used in ink form [32,33], Rz has been used recently as an aqueous solution to assess the photocatalytic activities of a number of different UV and visibleabsorbing semiconductor photocatalyst powders pressed as discs [34]. The overall reaction can be summarised as follows:

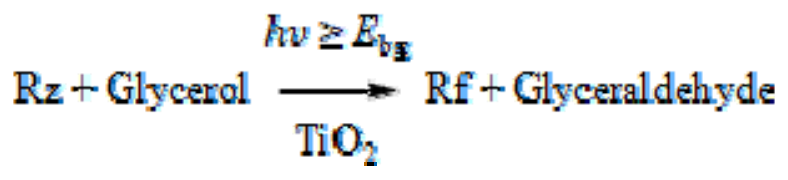

Blue

Pink

Thus, in this work, $3 \mathrm{~mL}$ of a $20 \mu \mathrm{M}$ aqueous solution of Resazurin (Rz) with $10 \mathrm{wt} \%$ glycerol were placed in the quartz cuvette 'photoreactor', used previously in the 4-CP study (see Figure $\mathrm{S} 2$ in supplementary information), with a $\mathrm{TiO}_{2}-\mathrm{SEN}$ plastic film in place as one of the 'windows', and purged with Ar before being sealed. As before, the UV-Vis absorption spectrum of the $\mathrm{Rz}$ in the reaction solution was monitored as a function of irradiation time $\left(42 \mathrm{~mW} \mathrm{~cm} \mathrm{~cm}^{-2}\right)$ and the results of this work are illustrated in Figure 7. The photo-induced changes in absorption spectra, show that, with increasing UV irradiation time, the absorbance at $602 \mathrm{~nm}$ (due to $\mathrm{Rz}$ ) decreases while, at the same time, the absorbance at $585 \mathrm{~nm}$ (due to Rf) increases. These observations are consistent with the $\mathrm{TiO}_{2}-\mathrm{SEN}$ plastic film photocatalysing reaction (3), as are the colours of the reaction solution recorded photographically: before, during and after irradiation, which are also illustrated in Figure 7. 


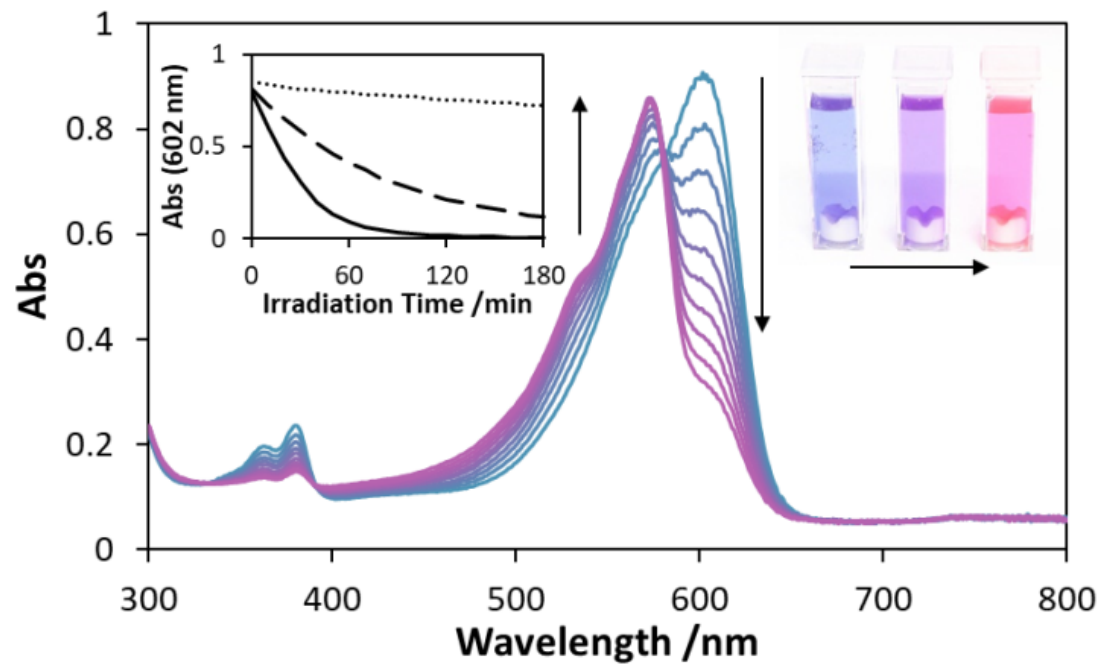

Figure 7. Typical UV-Vis absorption spectral changes of a Rz solution $(20 \mu \mathrm{M})$ in a quartz cuvette with a $\mathrm{TiO}_{2}$-SEN plastic film recorded as a function of UVA $(365 \mathrm{~nm})$ irradiation time $\left(42 \mathrm{~mW} \mathrm{~cm}^{-2}\right)$, where the spectra were recorded every $5 \mathrm{~min}$. The insert diagram shows the measured absorbance due to $\mathrm{Rz}$ at $602 \mathrm{~nm}$, $\operatorname{Abs}(602 \mathrm{~nm})$, recorded under the same experimental conditions as the main diagram, for the $\mathrm{TiO}_{2}-\mathrm{SEN}$ plastic film (solid line), Pilkington Activ ${ }^{\mathrm{TM}}$ glass (dashed line) and a blank polystyrene film (dotted line), as a function of irradiation time. Photographs of the reaction solution before, during and after UVA irradiation are also illustrated.

As before, a brief analysis of the decay kinetics exhibited by the two films (i.e. $\mathrm{TiO}_{2}-\mathrm{SEN}$ plastic film and Activ ${ }^{\mathrm{TM}}$ ), suggest that they are first order with respect to the concentration of $\mathrm{Rz}$, with first order rate constant, $\mathrm{k} 1$, values of $2.17 \pm 0.04$ and $0.68 \pm 0.004 \mathrm{~h}^{-1}$. The blank polystyrene film, as expected, did not reduce the Rz and thus showed no photoactivity.

The above work shows that the $\mathrm{TiO}_{2}-\mathrm{SEN}$ plastic film is, like Activ ${ }^{\mathrm{TM}}$, able to photocatalyse: (i) the oxidation of 4-CP, i.e. reaction (1), and MB, i.e. reaction (2), by oxygen and (ii) the photoreduction of Rz, i.e. reaction (3), by glycerol. The calculated values of $\mathrm{k}_{1}$ for these three reactions for the two films, along with the values of the activity ratio, $\mathrm{R}$, where $\mathrm{R}$ $=\mathrm{k}_{1}\left(\mathrm{TiO}_{2}-\mathrm{SEN}\right) / \mathrm{k}_{1}\left(\right.$ Activ $\left.^{\mathrm{TM}}\right)$, are given in Table 1 . 
Table 1. First order rate constants, $\mathrm{k}_{1}$ and $\mathrm{R}$ values for the $\mathrm{TiO}_{2}-\mathrm{SEN}$ plastic film and $\mathrm{Activ}^{\mathrm{TM}}$ samples when used to mediate the photooxidation of $4-\mathrm{CP}$ and $\mathrm{MB}$, as well as the photoreduction of Rz.

\section{First order rate constant, $k_{1}\left(h^{-1}\right)$}

\begin{tabular}{cccc}
\hline & 4-CP & MB & Rz \\
& $($ Reaction (1)) & (Reaction (2)) & (Reaction (3)) \\
\hline $\mathrm{TiO}_{2}$-SEN & $(22.2 \pm 0.2) \times 10^{-3}$ & $0.61 \pm 0.01$ & $2.17 \pm 0.04$ \\
Activ $^{\mathrm{TM}}$ & $(12.7 \pm 0.2) \times 10^{-3}$ & $0.20 \pm 0.01$ & $0.68 \pm 0.004$ \\
$\mathrm{R}$ & 1.75 & 3.05 & 3.19
\end{tabular}

From the values of $\mathrm{R}$ in Table 1 , it appears that in all cases the $\mathrm{TiO}_{2}$-SEN plastic film appears more active than Activ ${ }^{\mathrm{TM}}$ glass, and typically by 2-3 times.

\subsection{Rz Ink Test}

The most commonly used photocatalytic activity indicator ink (paii), used for testing photocatalytic films, contains $\mathrm{Rz}$ and glycerol as the key reaction ingredients and hydroxyethyl cellulose as a polymeric encapsulating agent. This Rz ink works in the same way as the Rz/glycerol solution experiment reported above, i.e. via reaction (3). However, in contrast to the Rz solution test, the Rz ink is very easily applied, quick to respond and easy to assess. As a result, it, and other paii's, are proving increasingly popular as a quick method for assessing the photocatalytic activities of surfaces [35-42].

In this work the $\mathrm{Rz}$ ink was used to assess the activities of the $\mathrm{TiO}_{2}$-SEN plastic film, Activ $^{\mathrm{TM}}$ and blank (PS only) film. The colour change is identical to that illustrated in Figure 7 for the $\mathrm{Rz}$ solution, and so the change in absorbance due to the Rz, Abs(608 nm), was monitored as a function of irradiation time (irradiance $=1.6 \mathrm{~mW} \mathrm{~cm}^{-2}$ ) for all three films and the results of this work are illustrated in Figure 8. Not surprisingly perhaps, the $\mathrm{TiO}_{2}-\mathrm{SEN}$ plastic film appeared more active than the sample of Activ ${ }^{\mathrm{TM}}$ glass $(\mathrm{R}=2.2)$ and the blank (PS) film exhibited no photocatalytic activity. 


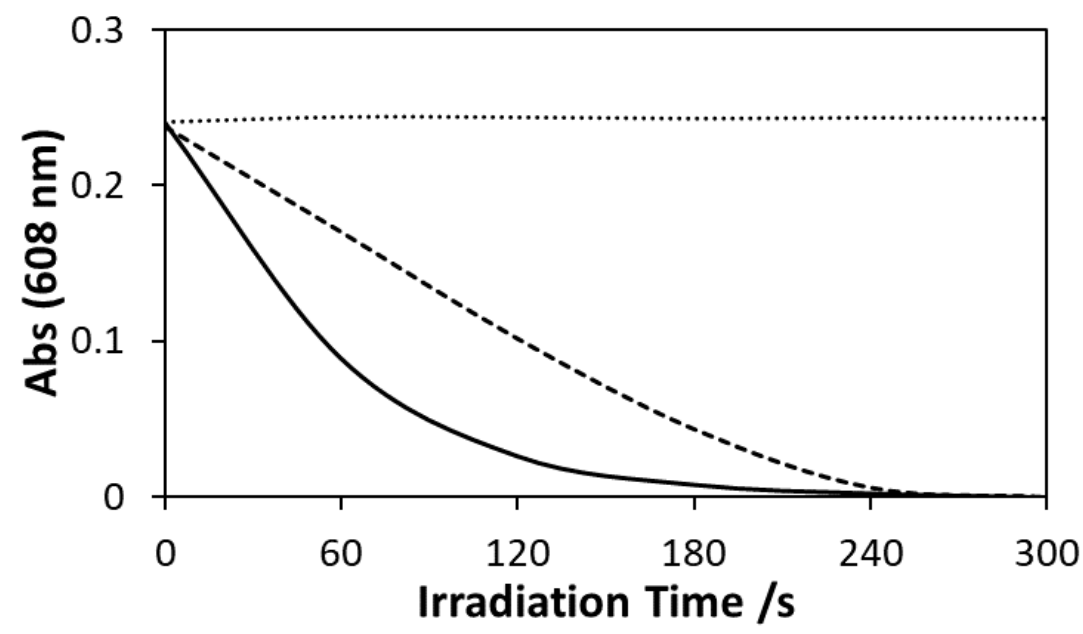

Figure 8. Max absorption of an $\mathrm{Rz}$ ink film on a $\mathrm{TiO}_{2}-\mathrm{SEN}$ plastic film (solid line), Pilkington Activ ${ }^{\mathrm{TM}}$ (dashed line) and a blank polystyrene film (dotted line) vs. time of UVA irradiation $\left(352 \mathrm{~nm}, 1.6 \mathrm{~mW} \mathrm{~cm}^{-2}\right)$.

A quick comparison of the decay profiles illustrated in Figure 7 and Figure 8 for what is ostensibly the same reaction, i.e. reaction (3), but in aqueous solution and the other in an ink, reveals a significant (26 times) decrease in reaction time, despite the fact that the irradiances used (42 cf. $1.6 \mathrm{~mW} \mathrm{~cm}^{-2}$ for solution and ink, respectively) would be expected to greatly favour the solution experiment. However, the ink film is much thinner and the Rz much more concentrated in the ink compared to that of the Rz solution, i.e. $2.1 \mu \mathrm{m} c f .1 \mathrm{~cm}$ and $42 \mathrm{mM}$ cf. $20 \mu \mathrm{M}$, and both of these conditions contribute to the much faster kinetics of the ink film and the popularity of the Rz paii test, which is just about to become as photocatalytic ISO test [43].

\subsection{MB Ink Test}

Much like the Rz/glycerol ink, a MB/glycerol ink can be used to probe photocatalytic activity in a substrate [44]. In this case the key reaction is:

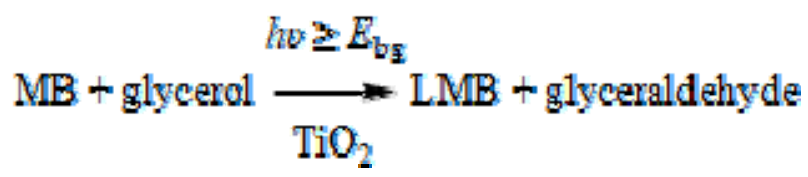

where, LMB is colourless leuco-methylene blue. However, unlike the photocatalysed reduction of $\mathrm{Rz}$, to $\mathrm{Rf}$, via reaction (3), that of $\mathrm{MB}$ is reversible, in that oxygen, if present, is able to re-oxidise the $\mathrm{LMB}$ to form $\mathrm{MB}$, i.e.

$$
\mathrm{LMB}+\frac{1}{2} \mathrm{O}_{2} \longrightarrow \mathrm{MB}+\mathrm{H}_{2} \mathrm{O}
$$


Thus, in this work the MB ink was used to coat the $\mathrm{TiO}_{2}-\mathrm{SEN}$ plastic film and was then

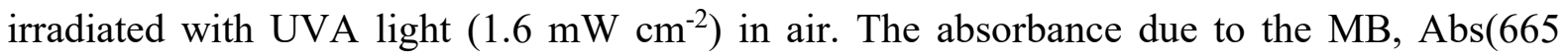
$\mathrm{nm}$ ), was then monitored as a function of irradiation time over a series of 3 light and dark cycles, and the results of this work are illustrated in Figure 9. These results show that the MB ink was bleached completely by the $\mathrm{TiO}_{2}$-SEN plastic film within three minutes UVA irradiation, even though the film was in air, as the MB is photocatalytically reduced to LMB via reaction (4). In the dark, still in air, the LMB was then more slowly re-oxidised to MB in 10 minutes, via reaction (5). As illustrated by the results in Figure 9, this process could be repeated several times with little evidence of deterioration in performance.

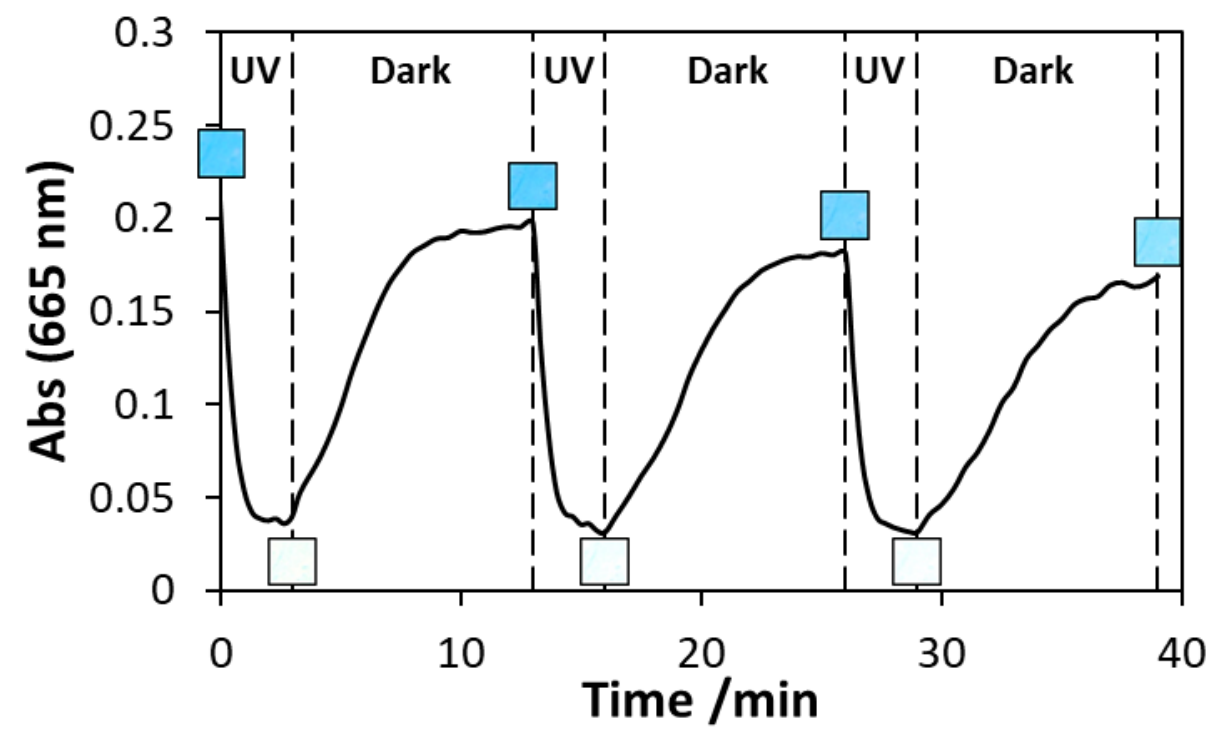

Figure 9. Response-recovery plot of an $\mathrm{MB}$ ink on a $\mathrm{TiO}_{2}-\mathrm{SEN}$ plastic film when irradiated with UVA light $\left(352 \mathrm{~nm}, 1.6 \mathrm{~mW} \mathrm{~cm}^{-2}\right)$. Sections of the film before and after each alternation of light and dark are placed at the respective points along the line.

Similar results were observed for the Activ ${ }^{\mathrm{TM}}$ glass and the blank film showed no sign of any photocatalytic activity.

\section{Conclusions}

Very thin $(2.5 \mu \mathrm{m})$ Surface-Exposed Nanoparticle (SEN) plastic films were successfully made from $\mathrm{TiO}_{2}$ P25 powder that are optically transparent, robust and flexible. Scanning electron microscopy shows that the $\mathrm{TiO}_{2}$ nanoparticles $(25.3 \pm 5.4 \mathrm{~nm})$ exist on just one side of the plastic film and are partially exposed to the ambient environment, while also partially embedded in the PS film; there are no nanoparticles on the other side. Various photocatalytic tests using 4-chlorophenol, methylene blue and resazurin in solution, as well as two ink tests 
( $\mathrm{Rz}$ and $\mathrm{MB}$ ), show that the $\mathrm{TiO}_{2}-\mathrm{SEN}$ plastic film is significantly (factor 2 or 3 ) more photoactive than a sample of Pilkington Activ $^{\mathrm{TM}}$, which has a similar optical clarity and a thin $(15 \mathrm{~nm})$ coating of photocatalytically-active $\mathrm{TiO}_{2}$, which underpins its 'self-cleaning' subriquet. This is the first example of the preparation and testing of photocatalytic $\mathrm{TiO}_{2}$ surface-exposed nanoparticle plastic films and, to our knowledge the production of so very thin, photocatalytically active plastic films. The photocatalytic activity and stability of these films is significant and suggests that they may find a more widespread use. The method of making such films is very simple and inexpensive and generic, thereby opening up the possibility of making SEN plastic films of other established and new photocatalytic materials. The method of production is new and so ease of scale up and possible manufacture is yet to be established.

\section{Appendix A: Supplementary Information}

The Supporting Information is available free of charge.

Digital image of a centrifuged P25 dispersion and a P25 dispersion of the same resulting loading. Irradiation setup schematic. SEM image of both sides of a $\mathrm{TiO}_{2}-\mathrm{SEN}$ plastic film.

\section{Author Information}

\section{Corresponding Author}

*E-mail: andrew.mills@qub.ac.uk.

\section{Notes}

The authors declare no competing financial interest.

\section{References}

[1] K.L. Kelly, E. Coronado, L.L. Zhao, G.C. Schatz, The Optical Properties of Metal Nanoparticles: The Influence of Size, Shape, and Dielectric Environment, J. Phys. Chem. B, 107 (2003) 668-677.

[2] S. Link, M.A. El-Sayed, Spectral Properties and Relaxation Dynamics of Surface Plasmon Electronic Oscillations in Gold and Silver Nanodots and Nanorods, J. Phys. Chem. B, 103 (1999) 8410-8426. 
[3] S.H. Sun, C.B. Murray, D. Weller, L. Folks, A. Moser, Monodisperse FePt Nanoparticles and Ferromagnetic FePt Nanocrystal Superlattices, Science, 287 (2000) 1989-1992.

[4] E. Roduner, Size Matters: Why Nanomaterials are Different, Chem. Soc. Rev., 35 (2006) 583-592.

[5] M.P. Pileni, Self-Assemblies of Nanocrystals: Fabrication and Collective Properties, Appl. Surf. Sci., 171 (2001) 1-14.

[6] D. Yogev, S. Efrima, Novel Silver Metal Liquidlike Films, J. Phys. Chem., 92 (1988) 5754-5760.

[7] S.E.J. Bell, J.J. McGarvey, S.J. Rigby, D.G. Walmsley, Raman-Scattering and Scanning Electron-Tunneling Studies of Metal Liquid-Like Films Produced from Silver and Gold Sols, J. Raman Spectrosc., 22 (1991) 763-769.

[8] H.W. Duan, D.Y. Wang, D.G. Kurth, H. Mohwald, Directing Self-Assembly of Nanoparticles at Water/Oil Interfaces, Angew. Chem., Int. Ed., 43 (2004) 5639-5642.

[9] Y. Xu, M.P. Konrad, W.W.Y. Lee, Z. Ye, S.E.J. Bell, A Method for Promoting Assembly of Metallic and Nonmetallic Nanoparticles into Interfacial Monolayer Films, Nano Lett., 16 (2016) 5255-5260.

[10] Y. Xu, M.P. Konrad, J.L. Trotter, C.P. McCoy, S.E.J. Bell, Rapid One-Pot Preparation of Large Freestanding Nanoparticle-Polymer Films, Small, 13 (2017) DOI:

10.1002/smll.201602163.

[11] S. Konstantinidis, J.P. Dauchot, A. Hecq, Titanium Oxide Thin Films Deposited by High-Power Impulse Magnetron Sputtering, Thin Solid Films, 515 (2006) 1182-1186.

[12] H. Yaghoubi, N. Taghavinia, E.K. Alamdari, Self Cleaning $\mathrm{TiO}_{2}$ Coating on Polycarbonate: Surface Treatment, Photocatalytic and Nanomechanical Properties, Surf. Coat. Tech., 204 (2010) 1562-1568.

[13] R. Fateh, R. Dillert, D. Bahnemann, Self-Cleaning Properties, Mechanical Stability, and Adhesion Strength of Transparent Photocatalytic $\mathrm{TiO}_{2}-\mathrm{ZnO}$ Coatings on Polycarbonate, ACS Appl. Mater. Interfaces, 6 (2014) 2270-2278.

[14] V. Bounor-Legaré, P. Cassagnau, In Situ Synthesis of Organic-Inorganic Hybrids or Nanocomposites from Sol-gel Chemistry in Molten Polymers, Prog. Polym. Sci., 39 (2014) 1473-1497.

[15] Pilkington, https://www.pilkington.com/en-gb/uk/products/product-categories/selfcleaning/pilkington-activ-range, in.

[16] TOTO, https://gb.toto.com/technology/technology-singleview/Technology/show/HYDROTECT/, in. 
[17] PhotoCityTex, http://photocitytex.eu/, in.

[18] HeidelbergCement Group, https://www.heidelbergcement.com/en, in.

[19] Sto South East Asia, http://www.sto-sea.com/en/company/innovations/sto-climasancolor/sto-climasan-color-.html, in.

[20] V.G. Bessergenev, I.V. Khmelinskii, R.J.F. Pereira, V.V. Krisuk, A.E. Turgambaeva, I.K. Igumenov, Preparation of $\mathrm{TiO}_{2}$ Films by CVD Method and its Electrical, Structural and Optical Properties, Vacuum, 64 (2002) 275-279.

[21] A. Mills, A. Lepre, N. Elliott, S. Bhopal, I.P. Parkin, S.A. O'Neill, Characterisation of the Photocatalyst Pilkington Activ (TM): A Reference Film Photocatalyst?, J. Photochem. Photobiol. A: Chem., 160 (2003) 213-224.

[22] B. Ohtani, O.O. Prieto-Mahaney, D. Li, R. Abe, What is Degussa (Evonik) P25? Crystalline Composition Analysis, Reconstruction from Isolated Pure Particles and Photocatalytic Activity Test, J. Photochem. Photobiol. A: Chem., 216 (2010) 179-182. [23] A. Salinaro, A.V. Emeline, J.C. Zhao, H. Hidaka, V.K. Ryabchuk, N. Serpone, Terminology, Relative Photonic Efficiencies and Quantum Yields in Heterogeneous Photocatalysis. Part II: Experimental Determination of Quantum Yields (Technical Report), Pure Appl. Chem., 71 (1999) 321-335.

[24] A. Mills, C. O'Rourke, K. Moore, Powder Semiconductor Photocatalysis in Aqueous Solution: An Overview of Kinetics-based Reaction Mechanisms, J. Photochem. Photobiol. A: Chem., 310 (2015) 66-105.

[25] RK Print, https://www.rkprint.com/wp-content/uploads/2018/02/New-K-HANDCOATER.pdf, in.

[26] R. Swanepoel, Determination of the Thickness and Optical-Constants of AmorphousSilicon, J. Phys. E: Sci. Instrum., 16 (1983) 1214-1222.

[27] M. Moonsiri, P. Rangsunvigit, S. Chavadej, E. Gulari, Effects of Pt and Ag on the Photocatalytic Degradation of 4-Chlorophenol and its By-Products, Chem. Eng. J., 97 (2004) 241-248.

[28] G. Al-Sayyed, J.-C. D'Oliveira, P. Pichat, Semiconductor-Sensitized Photodegradation of 4-Chlorophenol in Water, J. Photochem. Photobiol. A: Chem., 58 (1991) 99-114.

[29] ISO 10678. Fine ceramics (advanced ceramics, advanced technical ceramics) Determination of photocatalytic activity of surfaces in an aqueous medium by degradation of methylene blue, ISO, Geneva (2010). in. 
[30] X.L. Yan, T. Ohno, K. Nishijima, R. Abe, B. Ohtani, Is Methylene Blue an Appropriate Substrate for a Photocatalytic Activity Test? A Study with Visible-Light Responsive Titania, Chem. Phys. Lett., 429 (2006) 606-610.

[31] A. Mills, N. Wells, C. O'Rourke, Probing the Activities of UV and Visible-light Absorbing Photocatalyst Powders using a Resazurin-based Photocatalyst Activity Indicator Ink (Rz Paii), J. Photochem. Photobiol. A: Chem., 338 (2017) 123-133.

[32] A. Mills, N. Wells, Reductive Photocatalysis and Smart Inks, Chem. Soc. Rev., 44 (2015) 2849-2864.

[33] Wikipedia, https://en.wikipedia.org/wiki/Photocatalyst_activity_indicator_ink, in.

[34] M. Rochkind, S. Pasternak, Y. Paz, Using Dyes for Evaluating Photocatalytic Properties: A Critical Review, Molecules, 20 (2015) 88-110.

[35] S. In, A.H. Kean, A. Orlov, M.S. Tikhov, R.M. Lambert, A Versatile New Method for Synthesis and Deposition of Doped, Visible Light-Activated $\mathrm{TiO}_{2}$ Thin Films, Energy Environ. Sci., 2 (2009) 1277-1279.

[36] E.L. Cuéllar, A. Martinez-de la Cruz, K.H.L. Rodriguez, U.O. Méndez, Preparation of $\gamma$ $\mathrm{Bi}_{2} \mathrm{MoO}_{6}$ Thin Films by Thermal Evaporation Deposition and Characterization for Photocatalytic Applications, Catal. Today, 166 (2011) 140-145.

[37] S. Kundu, A. Kafizas, G. Hyett, A. Mills, J.A. Darr, I.P. Parkin, An Investigation into the Effect of Thickness of Titanium Dioxide and Gold-Silver Nanoparticle Titanium Dioxide Composite Thin Films on Photocatalytic Activity and Photo-induced Oxygen Production in a Sacrificial System, J. Mater. Chem., 21 (2011) 6854-6863.

[38] N. Farahani, P.J. Kelly, G. West, C. Hill, V. Vishnyakov, Photocatalytic Activity of Reactively Sputtered Titania Coatings Deposited Using a Full Face Erosion Magnetron, Coatings, 3 (2013) 177-193.

[39] X. Liu, J. Ma, J. Yang, Visible-Light-Driven Amorphous Fe(III)-Substituted Hydroxyapatite Photocatalyst: Characterization and Photocatalytic Activity, Mater. Lett., 137 (2014) 256-259.

[40] A.L. Anderson, R. Binions, The effect of Brij (R) Surfactants in Sol-gel Processing for the Production of $\mathrm{TiO}_{2}$ Thin Films, Polyhedron, 85 (2015) 83-92.

[41] E. Jimenez-Relinque, M. Castellote, Quantification of Hydroxyl Radicals on Cementitious Materials by Fluorescence Spectrophotometry as a Method to Assess the Photocatalytic Activity, Cem. Concr. Res., 74 (2015) 108-115. [42] C. Tupberg, N. Chandet, K. Wattanavichan, C. Randorn, Catalytic and Antibacterial Activities of Novel Colored Zinc Borophosphate Glasses, RSC Adv., 6 (2016) 79602-79611. 
[43] International Standards Organisation, https://www.iso.org/obp/ui/\#iso:std:69815:en, in. [44] A. Mills, J. Hepburn, M. McFarlane, A Novel, Fast-Responding, Indicator Ink for Thin Film Photocatalytic Surfaces, ACS Appl. Mater. Interfaces, 1 (2009) 1163-1165. 